\title{
Prognostic significance of positive peritoneal cytology in resectable pancreatic cancer: a systemic review and meta- analysis
}

\author{
Feng $\mathrm{Cao}^{1, *}$, Jia $\mathbf{L i}^{1, *}$, Ang $\mathbf{L i}^{1}$, Fei $\mathbf{L i}^{1}$ \\ ${ }^{1}$ Department of General Surgery, Xuanwu Hospital, Capital Medical University, Beijing 100053, PR China \\ *These authors contributed equally to this work
}

Correspondence to: Fei Li, email: feili36@ccmu.edu.cn

Keywords: pancreatic cancer, surgery, cytology, overall survival, meta-analysis

Received: September 20, 2016

Accepted: January 10, 2017

Published: January 19, 2017

\section{ABSTRACT}

\begin{abstract}
Although peritoneal cytology has been used to determine pancreatic cancer staging for more than three decades, its prognostic significance in potentially resectable pancreatic cancer is inconclusive. We therefore conducted this meta-analysis to investigate the impact of peritoneal cytology status on the clinicopathological features and survival outcomes in potentially resectable pancreatic cancer. Ten studies were identified for this meta-analysis after searching the PubMed, Web of Science and China National Knowledge Infrastructure (CNKI) electronic databases. Our results showed that positive peritoneal cytology was associated with tumor size (OR 11.65, $P=0.001)$, tumor location (OR 0.37, $P=0.000$ ), serosal invasion (OR 3.89, $P=0.000$ ), portal vein invasion (OR 1.82, $P=0.016$ ), lymph vessel invasion (OR $2.71, P=0.026$ ), $\mathrm{T}$ stage (OR 2.65, $P=0.037$ ) and $N$ stage (OR 2.34, $P=0.001)$ in resectable pancreatic cancer. Patients with positive peritoneal cytology demonstrated poor overall survival (OS; HR $3.18, P=0.000$ ) and disease-free survival (DFS; HR 2.88, $P=0.000$ ) times. Based on our meta-analysis, we conclude that positive peritoneal cytology is an indicator of advanced stage pancreatic cancer with a poor prognosis; hence, radical resection should not be performed on these patients.
\end{abstract}

\section{INTRODUCTION}

Pancreatic cancer is one of the leading causes of cancer-related mortality worldwide [1-3]. Although surgical resection is the only curable option, less than $20 \%$ of the patients diagnosed with localized disease are resectable. The prognosis of these patients after complete resection is extremely poor due to local and systemic recurrence $[1,4]$. Since pre-operative imaging is inaccurate, re-staging the tumor based on laparoscopy, para-aortic lymph node sampling and intra-operative peritoneal cytology (CY) can rule out patients with occult tumor metastasis from unnecessary pancreatic resection [5-7].

Peritoneal cytology (CY) has been widely used in diagnosis and staging of ovarian, endometrial and gastric cancers [8-10]. In resectable pancreatic cancer patients, the incidence of positive peritoneal cytology $(\mathrm{CY}+)$ was 7-30\% [11-20]. However, the prognostic significance of $\mathrm{CY}+$ in potentially resectable pancreatic cancer is controversial. Some studies from Japan reported that CY+ without distant metastasis should not preclude resection in resectable pancreatic cancer patients and that long-term survival was possible after adjuvant chemotherapy $[15,16$, 20]. In contrast, several other studies showed that patients with CY+ status were associated with advanced disease and poor prognosis and had survival rates equivalent to other stage IV diseases [11-14]. Due to these inconsistent conclusions, the American Joint Committee on Cancer and treatment guideline from the National Comprehensive Cancer Network considered CY+ as stage IV metastasis and contraindicator for pancreatic resection [21, 22]. However, the Pancreas Society in Japan did not include the CY status in stage evaluations to classify pancreatic cancer [23]. Therefore, in this study, we conducted this systemic review and meta-analysis to clarify the clinicopathological and prognostic significance of $\mathrm{CY}+$ in resectable pancreatic cancer. 


\section{RESULTS}

\section{Search results and study characteristics}

Initially, 949 records were identified by searching the databases and other sources using the relevant terms as described in the methods section. After screening the title and abstract, 30 full-text articles were assessed for eligibility and 10 retrospective studies that met the inclusion criteria were included in this meta-analysis (Figure 1).

The characteristics of the included studies are summarized in Table 1 . Of the 10 studies, 8 were from Japan and 2 from the USA. Combined, $228 \mathrm{CY}+$ and 2294 CY- patients were included in these studies and the incidence of CY+ was $11.8 \%$. Papanicolaou and Giemsa staining were the most commonly used cytology methods. The follow-up time for the $\mathrm{CY}+$ group ranged from 11 to 37 months with OS of 6-23.8 months, whereas, the CYgroup had a OS of 16-36.4 months. Based on NewcastleOttawa quality assessment, three studies achieved 7 or more stars and were considered as high quality (Supplementary Table 1).

\section{Meta-analysis results}

\section{CY+ and clinicopathological characteristics}

To explore the association between $\mathrm{CY}+$ and clinicopathological features in resectable pancreatic cancer, binary meta-analysis was performed with ORs indicating outcomes. The results are summarized in Table 2. In brief, $\mathrm{CY}+$ significantly correlated with tumor size (OR $95 \% \mathrm{CI}$, 11.65 (2.62-51.86.93); $P=0.001$ ), tumor location (OR 95\% CI, 0.37 (0.27-0.52); $P=0.000)$, serosal invasion (OR 95\% CI, 3.89 (2.26-6.71); $P=0.000)$, portal vein invasion (OR 95\% CI, 1.82(1.12-2.95); $P=0.016$ ), lymph vessel invasion (OR 95\% CI, $2.71(1.13-6.50) ; P=0.026)$, T stage (OR 95\% CI, $2.65(1.06-6.63) ; P=0.037)$ and $\mathrm{N}$ stage (OR 95\% CI, $2.34(1.44-3.82) ; P=0.001)$.

\section{$\mathrm{CY}+$ and recurrence in resectable pancreatic cancer}

Four of the ten studies reported the relationship between $\mathrm{CY}+$ and total recurrence $[11,12,14,18]$. Since there was no significant heterogeneity $\left(P=0.205, \mathrm{I}^{2}=\right.$ $36.4 \%$ ), the fixed-effect model was used for analysis. Our results revealed that $\mathrm{CY}+$ was associated with total recurrence (OR 95\% CI, 5.21 (2.45-11.00); $P=0.000$ ). Further, we explored the correlation between the $\mathrm{CY}$ status and local recurrence or liver metastasis that was reported in four studies $[12,14,16,18]$. Since no significant heterogeneity was detected $\left(P=0.983, \mathrm{I}^{2}=0 \%\right.$ for local recurrence; $P=0.556, \mathrm{I}^{2}=0 \%$ for liver metastasis and $P=$ $0.662, \mathrm{I}^{2}=0 \%$ for peritoneum recurrence), the fixed-effect model was used for meta-analyses. Our analysis detected no correlation between $\mathrm{CY}+$ and local recurrence (OR 95\% CI, $1.01(0.60-1.70) ; P=0.973)$ or liver metastasis (OR 95\% CI, 0.75 (0.47-1.19); $P=0.214)$. However, CY+ status was associated with peritoneum recurrence (OR 95\% CI, 4.57 (3.08-6.78); $P=0.000$; Table 3, Figure 2).

\section{$\mathrm{CY}+$ and $\mathrm{OS}$ in resectable pancreatic cancer}

All the 10 included studies reported the OS data with 228 and 2294 patients in CY+ and CY- groups, respectively [11-20]. Since the data were heterogeneous $\left(P=0.000, \mathrm{I}^{2}=89.4 \%\right)$, a random-effect model was used. The pooled HR for OS showed that $\mathrm{CY}+$ in resectable pancreatic cancer was associated with poor OS (HR 95\%CI, 3.18(1.88-5.39; $P=0.000)$ (Table 3, Figure 3).

\section{CY+ and DFS in resectable pancreatic cancer}

Five of the ten studies reported the DFS data with $128 \mathrm{CY}+$ patients and $1427 \mathrm{CY}$ - patients $[11,12,14,16,18]$. The fixed effect model was used for analysis as significant heterogeneity was not detected $\left(P=0.302, \mathrm{I}^{2}=17.7 \%\right)$. Our analysis demonstrated that $\mathrm{CY}+$ status was associated with poor DFS (HR 95\%CI, 2.88(2.39-3.49); $P=0.000$ ) in resectable pancreatic cancer patients (Table 3, Figure 4). The results of the subgroup analysis were consistent with the overall analysis and are summarized in Table 3.

\section{Publication bias}

Begg's test showed no publication bias in the studies used for the meta-analysis with OS $(P=0.142)$ and DFS $(P=0.129)$ as shown in Figure 5.

\section{DISCUSSION}

The increased incidence of $\mathrm{CY}+$ from $7-30 \%$ in resectable to $20-57 \%$ in unresectable pancreatic cancer $[11-20,24]$ suggested that $\mathrm{CY}+$ patients had greater tumor burden and represented a more advanced stage of cancer. Previously, $\mathrm{CY}+$ was associated with high pre-operative CA19-9 levels [12], larger tumors [12, 13, 15, 20, 25], tumor location in the body/tail of the pancreas $[12,13$, 26], lymph node metastasis [12], vascular invasion [11], serosal invasion $[15,16]$ and late TNM stage $[13,26]$. Our results showed that $\mathrm{CY}+$ was more frequent in advanced resectable pancreatic cancer patients and was significantly associated with larger tumor size (OR 11.65, $P=0.001$ ), tumor located in pancreatic head (OR $0.37, P=0.000$ ), serosal invasion (OR 3.89, $P=0.000$ ), portal vein invasion (OR 1.82, $P=0.016$ ), lymph vessel invasion (OR 2.71, $P=0.026$ ), T stage (OR 2.65, $P=0.037$ ) and $\mathrm{N}$ stage (OR $2.34, P=0.001)$.

The prognosis of pancreatic cancer with synchronous peritoneal metastasis was extremely poor 
Table 1: Characteristics of studies included in the meta-analysis

\begin{tabular}{|c|c|c|c|c|c|c|c|c|c|c|}
\hline Author & Year & Country & Method of cytology & $\begin{array}{l}\text { No. of patients } \\
(\mathrm{CY}+\mathrm{vs} \text { CY-) }\end{array}$ & $\begin{array}{c}\text { Median } \\
\text { follow-up } \\
\text { (months) }\end{array}$ & $\begin{array}{l}\text { Median survival } \\
\text { (months) }\end{array}$ & $\begin{array}{l}\text { Adjuvant } \\
\text { therapy }\end{array}$ & $\begin{array}{c}\text { Multivariate/ } \\
\text { Univariate }\end{array}$ & HR(95\%CI) & $\begin{array}{l}\text { Quality of } \\
\text { study }\end{array}$ \\
\hline Iwagami [11] & 2015 & Japan & Papanicolaou staining & $5 / 34$ & $31.0(5.4-113.9)$ & $\begin{array}{l}\text { OS: } 13.3 \text { vs } 36.4 \\
\text { RFS: } 6.5 \text { vs } 15.7\end{array}$ & \begin{tabular}{|c|} 
Gemcitabine based \\
chemotherapy: \\
$100 \%$ vs $55.9 \%$
\end{tabular} & Multivariate & $\begin{array}{c}\text { OS }: 2.589(0.734- \\
8.532) \\
\text { RFS:5.100(1.279- } \\
20.925) \\
\end{array}$ & 8 \\
\hline Satoi [12] & 2015 & Japan & $\begin{array}{l}\text { Papanicolaou and/or } \\
\text { Giemsa staining }\end{array}$ & $69 / 915$ & 19.7 & $\begin{array}{l}\text { OS: } 16.0 \text { vs } 24.9 \\
\text { DFS: } 8.8 \text { vs } 13.8\end{array}$ & $\begin{array}{c}\text { Gemcitabine } \\
\text { or S-1 based } \\
\text { chemotherapy: } \\
86 \% \text { vs } 82 \%\end{array}$ & Multivariate & OS:0.74 $(0.55-0.98)^{5}$ & 6 \\
\hline Hirabayas hi [13] & 2015 & Japan & $\begin{array}{l}\text { Papanicolaou and/or } \\
\text { Giemsa staining }\end{array}$ & $18 / 141$ & NA & OS: 10 vs 27 & NA & Multivariate & OS:2.711(1.464-5.022) & 6 \\
\hline Aoyama [14] & 2015 & Japan & Papanicolaou staining & $21 / 122$ & $37(4.4-110.5)$ & $\begin{array}{c}5 \text { ys OS: } 8.6 \% \text { vs } \\
16.1 \% \\
\text { 5 ys RFS: } 0 \% \text { vs } \\
16.1 \% \\
\end{array}$ & $\begin{array}{c}\text { Gemcitabine } \\
\text { or S-1 based } \\
\text { chemotherapy: } \\
100 \%\end{array}$ & Univariate & $\begin{array}{c}\text { OS: } 1.370(0.796-2.361) \\
\text { RFS:2.360(1.427- } \\
3.904)\end{array}$ & 7 \\
\hline Yamada [15] & 2013 & Japan & $\begin{array}{l}\text { Papanicolaou and } \\
\text { Giemsa staining }\end{array}$ & $51 / 339$ & 15.7 & OS: $14 \cdot 3$ vs $18 \cdot 0$ & $\begin{array}{c}\text { Gemcitabine } \\
\text { or S-1 based } \\
\text { chemotherapy: } \\
53.3 \% \\
\end{array}$ & Multivariate & OS: $1.36(0.94-1.90)^{\&}$ & 6 \\
\hline Yoshioka [16] & 2012 & Japan & Papanicolaou staining & $20 / 234$ & $24.7(0.8-97.4)^{*}$ & $\begin{array}{l}\text { OS: } 23.8 \text { vs } 26.5 \\
\text { RFS: } 8.1 \text { vs } 13.5 \\
\end{array}$ & $\begin{array}{l}\text { Chemotherapy: } \\
80.0 \% \text { vs } 70.9 \%\end{array}$ & NA & NA & 8 \\
\hline Ferrone [17] & 2006 & US & NA & $77 / 385^{\dagger}$ & $11(0-122)$ & OS: 8 vs 16 & $\begin{array}{c}\text { In resected } \\
\text { patients: } 49 \%\end{array}$ & NA & NA & 6 \\
\hline Meszoely [18] & 2004 & US & $\begin{array}{c}\text { H\&E and } \\
\text { Papanicolaou staining }\end{array}$ & $27 / 141^{\ddagger}$ & NA & $\begin{array}{l}\text { OS: } 15 \text { vs } 19 \\
\text { DFS: } 10 \text { vs } 12\end{array}$ & $\begin{array}{c}5 \text {-FU based } \\
\text { chemotherapy: } \\
60 \% \text { in resected } \\
\text { tumors } \\
\end{array}$ & NA & NA & 6 \\
\hline Konishi [19] & 2002 & Japan & Papanicolaou staining & $36 / 115^{\#}$ & NA & OS:NA & $\begin{array}{l}\text { IORT }(+E R B T+5- \\
\text { FU) in local } \\
\text { advanced and } \\
\text { metastatic tumor: } \\
100 \%\end{array}$ & NA & NA & 6 \\
\hline Yachida [20] & 2002 & Japan & $\begin{array}{l}\text { Papanicolaou, Giemsa } \\
\text { and Alcian blue } \\
\text { staining, ICH }\end{array}$ & $16 / 114$ & NA & OS: 18 vs 15 & $\begin{array}{l}\text { Mitomycin C } \\
\text { or 5-FU based } \\
\text { chemotherapy in } \\
12 \text { patients with } \\
\text { R1 resection }\end{array}$ & NA & NA & 6 \\
\hline
\end{tabular}

"presented with mean (range). ${ }^{\dagger}$ there were 10 and 217 resected patients in $\mathrm{Cy}+$ and $\mathrm{Cy}$ - groups, respectively. ${ }^{\ddagger}$ there were 13 and 122 resected patients in $\mathrm{Cy}+$ and $\mathrm{Cy}-$ groups, respectively." there were 5 and 56 resected patients in $\mathrm{Cy}+$ and $\mathrm{Cy}$ - groups, respectively. ${ }^{8}$ presented with $\mathrm{Cy}-\mathrm{vs} \mathrm{Cy}+.{ }^{*}$ for resected tumors. NA not available.

with a median survival of 6 weeks $(95 \%$ CI, 5-7weeks) and no improvement inspite of chemotherapy [27]. In the gastric, colon and gynecological malignancies, microscopic occult peritoneal metastases preceded the emergence of macroscopic metastases and such patients were precluded from radical surgery $[8,28-30]$. However, the impact of $\mathrm{CY}+$ on long-term survival of pancreatic cancer was uncertain. Some surgeons from Japan believed that $\mathrm{CY}+$ status in the absence of other distant metastasis was not a contraindication for radical surgery and that surgical resection offered a chance for long-term survival $[15,16,20,25]$. In contrast, other studies suggested that patients with $\mathrm{CY}+$ experienced peritoneal recurrence and poor survival time inspite of radical surgery and adjuvant chemotherapy [11-14]. In a recent large-scale multicenter study with 984 cases receiving R0 resection, Satoi and colleagues reported that $\mathrm{OS}$ of $\mathrm{CY}+$ patients (median survival time: 16 months; 3 year OS rate: $6 \%$ ) was worse than $\mathrm{CY}-$ patients (median survival time: 25 months; 3-year OS rate: $37 \% ; p<0.001)$. Also, CY+ patients demonstrated higher post-operative peritoneal carcinomatosis $(48 \%)$ than the CY- patients $(21 \%$; $p<0.001$ ) [12]. Our data revealed that $\mathrm{CY}+$ status was a risk factor for poor OS (HR 3.18, $P=0.000$ ), DFS (HR 2.88, $P=0.000$ ) with high total recurrence (HR 5.21, $P=0.000$ ) and peritoneal recurrence (HR 4.57, $P=0.000$ ) in patients with resectable tumor. Although some surgeons from Japan performed more aggressive resection for pancreatic cancer than those from US, the OS of Japan patients was similar with US patients. Our subgroup analysis still revealed that $\mathrm{CY}+$ was a predictor of shorter OS and DFS with a higher recurrence rate in Japan patients.

The median OS time in resectable $\mathrm{CY}+$ patients ranged from 8-23.8 months $[16,17]$ that was better than the 6.7-17 months range for the metastatic pancreatic cancer patients receiving either gemcitabine, nabpaclitaxel plus gemcitabine or Folfirinox chemotherapy [31-33]. However, the prognosis of CY+ patients who underwent pancreatic resection was poorer than the locally advanced tumor patients receiving aggressive modern chemotherapy without surgery with a median OS time was 10.0-32.7 months [34, 35]. Also, $\mathrm{CY}+$ patients failed to display long-term DFS upon resection of the primary tumor. Therefore, $\mathrm{CY}+$ was equivalent to $\mathrm{M} 1$ disease and radical surgery was not advisable.

Since unnecessary pancreatic resection could delay the induction of chemotherapy that would adversely affect patient survival [34]. In a recently updated Cochrane systemic review, prior diagnostic laparoscopy with biopsy and histopathological confirmation of suspicious lesions resulted in avoiding 21\% unnecessary laparotomies planned with a curative intent for cancer resection [35]. 
Table 2: Clinicopathological characteristics of $\mathrm{CY}+$ and $\mathrm{CY}$ - patients with resectable pancreatic cancer

\begin{tabular}{|c|c|c|c|c|c|c|c|c|c|}
\hline \multirow[t]{2}{*}{ Outcome } & \multirow[t]{2}{*}{ Ref. included } & \multirow{2}{*}{$\begin{array}{c}\text { No. of patients } \\
\text { (CY+ vs CY-) }\end{array}$} & \multicolumn{3}{|c|}{ Heterogeneity test } & \multirow[t]{2}{*}{ Model used } & \multirow[t]{2}{*}{ OR } & \multirow[t]{2}{*}{$95 \% \mathrm{CI}$} & \multirow[t]{2}{*}{$P$ value } \\
\hline & & & $\begin{array}{l}\text { Chi- } \\
\text { square }\end{array}$ & $P$ value & I-square & & & & \\
\hline Age (older vs younger) & {$[11,13,15]$} & 74 vs 514 & 7.83 & 0.020 & $74.5 \%$ & Random model & 2.40 & $0.38-15.38$ & 0.354 \\
\hline Sex (male vs female) & {$[11-16,18]$} & 211 vs 1926 & 10.14 & 0.119 & $40.8 \%$ & Fixed model & 0.96 & $0.71-1.29$ & 0.762 \\
\hline Tumor size (larger vs smaller) & {$[11,13,15,16]$} & 94 vs 748 & 9.79 & 0.020 & $69.4 \%$ & Random model & 11.65 & $2.62-51.86$ & 0.001 \\
\hline Tumor location (head vs body/tail) & {$[11-15,18]$} & 177 vs 1673 & 6.60 & 0.169 & $39.4 \%$ & Fixed model & 0.37 & $0.27-0.52$ & 0.000 \\
\hline Tumor grade (poor vs well//moderate) & {$[11,13,14,16]$} & 64 vs 531 & 1.71 & 0.635 & $0 \%$ & Fixed model & 0.89 & $0.40-1.97$ & 0.776 \\
\hline Retroperitoneal invasion (Yes or No) & {$[11,15,16,20]$} & 92 vs 721 & 2.64 & 0.450 & $0 \%$ & Fixed model & 1.63 & $0.97-2.72$ & 0.063 \\
\hline Serosal invasion(yes or no) & {$[11,15,16,20]$} & 92 vs 721 & 4.27 & 0.234 & $29.7 \%$ & Fixed model & 3.89 & $2.26-6.71$ & 0.000 \\
\hline Portal vein invasion(yes or no) & {$[11,15,16]$} & 76 vs 606 & 2.45 & 0.294 & $18.2 \%$ & Fixed model & 1.82 & $1.12-2.95$ & 0.016 \\
\hline Arterial invasion(yes or no) & {$[11,15,16]$} & 76 vs 606 & 1.83 & 0.401 & $0 \%$ & Fixed model & 1.85 & $0.86-3.96$ & 0.115 \\
\hline Lymph vessel invasion(yes or no) & {$[11,13,14]$} & 44 vs 297 & 0.34 & 0.842 & $0 \%$ & Fixed model & 2.71 & $1.13-6.50$ & 0.026 \\
\hline Perineural invasion(yes or no) & {$[11,13,15,16]$} & 94 vs 748 & 1.11 & 0.776 & $0 \%$ & Fixed model & 0.93 & $0.53-1.61$ & 0.785 \\
\hline Venous invasion(yes or no) & {$[11,13,14]$} & 44 vs 297 & 2.51 & 0.285 & $20.3 \%$ & Fixed model & 2.80 & $1.06-7.41$ & 0.285 \\
\hline T stage(T3+4 vs T1+2) & {$[11-14,19]$} & 118 vs 1268 & 0.62 & 0.961 & $0 \%$ & Fixed model & 2.65 & $1.06-6.63$ & 0.037 \\
\hline $\mathrm{N}$ stage(N1 vs N0) & {$[11-14,19]$} & 118 vs 1268 & 6.33 & 0.176 & $36.8 \%$ & Fixed model & 2.34 & $1.44-3.82$ & 0.001 \\
\hline
\end{tabular}

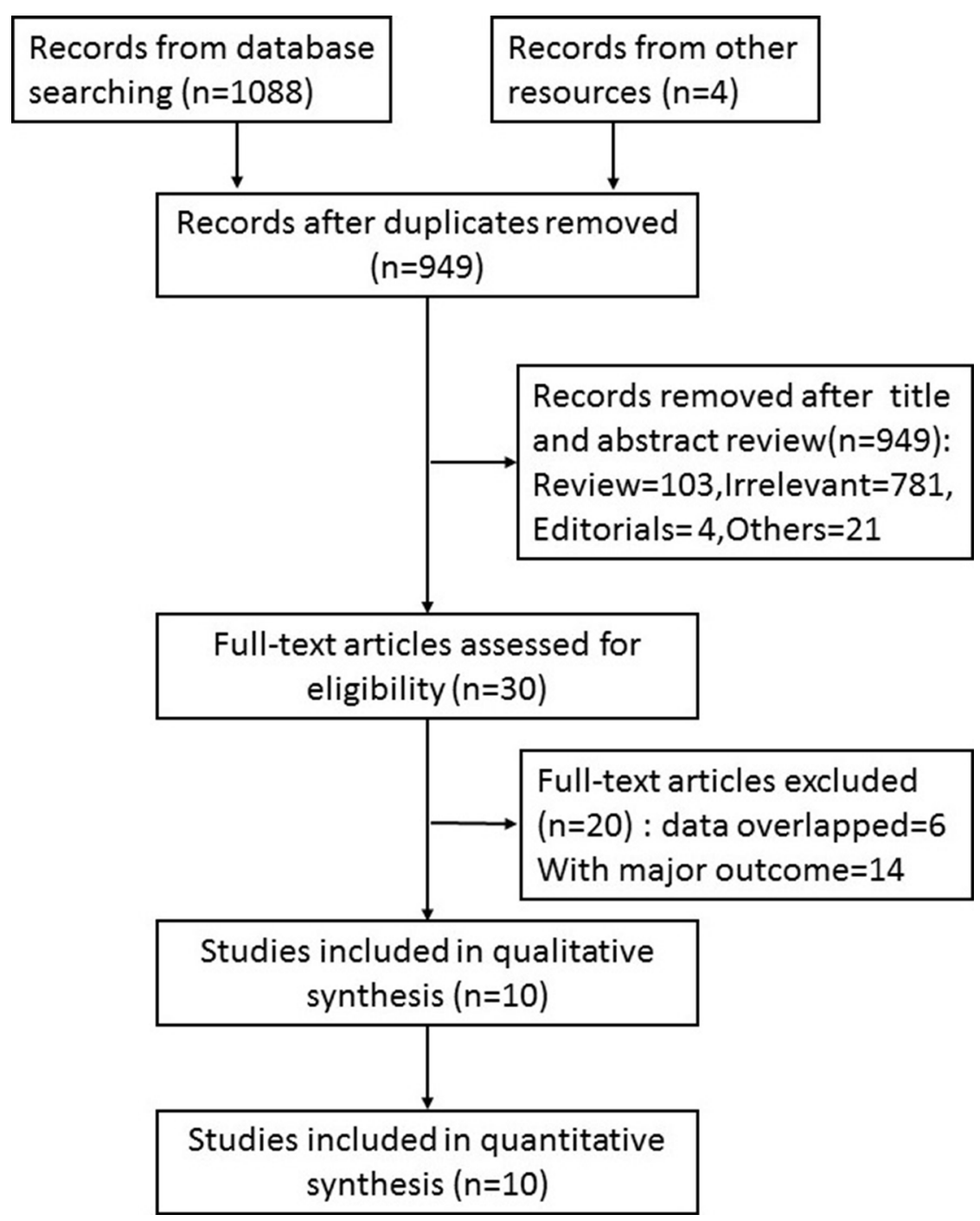

Figure 1: Flow chart showing selection criteria for including studies in the meta-analysis. 
Table 3: Meta-analysis results for OS, DFS and peritoneum recurrence

\begin{tabular}{|c|c|c|c|c|c|c|c|c|c|}
\hline \multirow[t]{2}{*}{ Outcome } & \multirow[t]{2}{*}{ Ref. included } & \multirow{2}{*}{$\begin{array}{l}\text { No. of patients } \\
(\mathrm{CY}+\text { vs CY-) }\end{array}$} & \multicolumn{3}{|c|}{ Heterogeneity test } & \multirow[t]{2}{*}{ Model used } & \multirow[t]{2}{*}{ HR } & \multirow[t]{2}{*}{$95 \% \mathrm{CI}$} & \multirow[t]{2}{*}{$P$ value } \\
\hline & & & $\begin{array}{c}\text { Chi- } \\
\text { square }\end{array}$ & $P$ value & I-square & & & & \\
\hline OS & {$[11-20]$} & 228 vs 2294 & 85.08 & 0.000 & $89.4 \%$ & Random model & 3.18 & $1.88-5.39$ & 0.000 \\
\hline \multicolumn{10}{|l|}{ Quality of research } \\
\hline High & {$[11,14,16]$} & 46 vs 390 & 5.77 & 0.056 & $65.3 \%$ & Random model & 2.31 & $1.11-4.83$ & 0.026 \\
\hline Low & {$[12,13,15,17-20]$} & 182 vs 1904 & 56.60 & 0.000 & $89.2 \%$ & Random model & 4.06 & $2.00-8.24$ & 0.000 \\
\hline \multicolumn{10}{|l|}{ Origin of research } \\
\hline Japan & {$[11-16,19,20]$} & 205 vs 1955 & 41.57 & 0.000 & $83.2 \%$ & Random model & 2.42 & $1.53-3.82$ & 0.000 \\
\hline US & {$[17,18]$} & 23 vs 339 & 3.12 & 0.077 & $68.0 \%$ & Random model & 9.07 & $3.98-20.69$ & 0.000 \\
\hline \multicolumn{10}{|l|}{ Adjuvant chemotherapy } \\
\hline Gemcitabine based & {$[11,12,14,15]$} & 146 vs 1410 & 1.04 & 0.792 & $0 \%$ & Fixed model & 1.38 & $1.13-1.69$ & 0.002 \\
\hline Others & {$[13,16-20]$} & 82 vs 884 & 16.18 & 0.006 & $69.1 \%$ & Random model & 5.28 & $3.28-8.49$ & 0.000 \\
\hline DFS & {$[11,12,14,16,18]$} & 128 vs 1427 & 4.86 & 0.302 & $17.7 \%$ & Fixed model & 2.88 & $2.39-3.49$ & 0.000 \\
\hline \multicolumn{10}{|l|}{ Quality of research } \\
\hline High & {$[11,14,16]$} & 46 vs 390 & 2.40 & 0.301 & $16.7 \%$ & Fixed model & 3.09 & $2.16-4.44$ & 0.000 \\
\hline Low & {$[12,18]$} & 82 vs 1037 & 2.26 & 0.133 & $55.7 \%$ & Random model & 3.25 & $1.84-5.76$ & 0.000 \\
\hline \multicolumn{10}{|l|}{ Origin of research } \\
\hline Japan & {$[11,12,14,16]$} & 115 vs 1305 & 2.86 & 0.414 & $0 \%$ & Fixed model & 2.79 & $2.29-3.39$ & 0.000 \\
\hline US & {$[18]$} & 13 vs 122 & NA & NA & NA & Fixed model & 5.00 & $2.28-10.98$ & 0.000 \\
\hline \multicolumn{10}{|l|}{ Adjuvant chemotherapy } \\
\hline Gemcitabine based & {$[11,12,14]$} & 95 vs 1071 & 1.05 & 0.591 & $0 \%$ & Fixed model & 2.65 & $2.15-3.26$ & 0.000 \\
\hline Others & & 33 vs 356 & 0.21 & 0.646 & $0 \%$ & Fixed model & 4.31 & $2.73-6.79$ & 0.000 \\
\hline Peritoneum recurrence & {$[12,14,16,18]$} & 123 vs 1393 & 1.59 & 0.662 & $0 \%$ & Fixed model & 4.57 & $3.08-6.78$ & 0.000 \\
\hline Quality of research & {$[16,18]$} & & & & & & & & \\
\hline High & {$[14,16]$} & 41 vs 356 & 1.54 & 0.215 & $35 \%$ & Fixed model & 4.27 & $2.06-8.86$ & 0.000 \\
\hline Low & {$[12,18]$} & 82 vs 1037 & 0.06 & 0.800 & $0 \%$ & Fixed model & 4.70 & $2.94-7.50$ & 0.000 \\
\hline \multicolumn{10}{|l|}{ Origin of research } \\
\hline Japan & {$[12,14,16]$} & 110 vs 1271 & 1.54 & 0.464 & $0 \%$ & Fixed model & 4.64 & $3.06-7.05$ & 0.000 \\
\hline US & {$[18]$} & 13 vs 122 & NA & NA & NA & Fixed model & 4.10 & $1.27-13.24$ & 0.018 \\
\hline \multicolumn{10}{|l|}{ Adjuvant chemotherapy } \\
\hline Gemcitabine based & {$[12,14]$} & 90 vs 1037 & 0.74 & 0.389 & $0 \%$ & Fixed model & 4.33 & $2.75-6.81$ & 0.000 \\
\hline Others & {$[16,18]$} & 33 vs 356 & 0.54 & 0.464 & $0 \%$ & Fixed model & 5.42 & $2.44-12.00$ & 0.000 \\
\hline
\end{tabular}

Similarly, we recommend the routine use of staging laparoscopy and peritoneal washing cytology examination in patients with resectable pancreatic cancer to detect occult tumors and avoid unnecessary surgery.

When intra-operative cytology results are unavailable, we propose that patients receive adjuvant chemotherapy as soon as $\mathrm{CY}+$ status is confirmed. In cases where $\mathrm{CY}+$ status is observed during operation, intra-operative HIPEC (hyperthermic intraperitoneal chemotherapy) followed by adjuvant chemotherapy should be considered to effectively control the local recurrences $[36,37]$. Also, the $\mathrm{CY}+$ patients should be treated as M1 postoperatively regardless of status of primary tumor.

Although molecular targeted therapy has been extensively evaluated, so far they have been ineffective in pancreatic cancer. EGFR inhibition using erlotinib is the only trial that demonstrated improved survival[38].
Pancreatic cancer has been refractory to immunotherapy through CTLA-4, PD-1 or PD-L1 antibodies that have been promising for many advanced solid tumors $[39,40]$. Data from several new agents is currently under investigation and the results are expected in the next year or two.

In unresected $\mathrm{CY}+$ tumors without other macrometastasis, re-staging laparoscopy should be considered in patients showing favorable response to chemotherapy. If CY- status is confirmed, pancreatic resection can be performed. Recent studies showed that resection of the primary tumor in metastatic pancreatic adenocarcinoma patients following favorable response to systemic chemotherapy resulted in improved survival $[41,42]$.

This meta-analysis had several limitations. First, significant heterogeneity was observed among the 


\section{OR of peritoneum recurrence}

Study

ID
$\mathrm{OR}(95 \% \mathrm{Cl})$

Weight

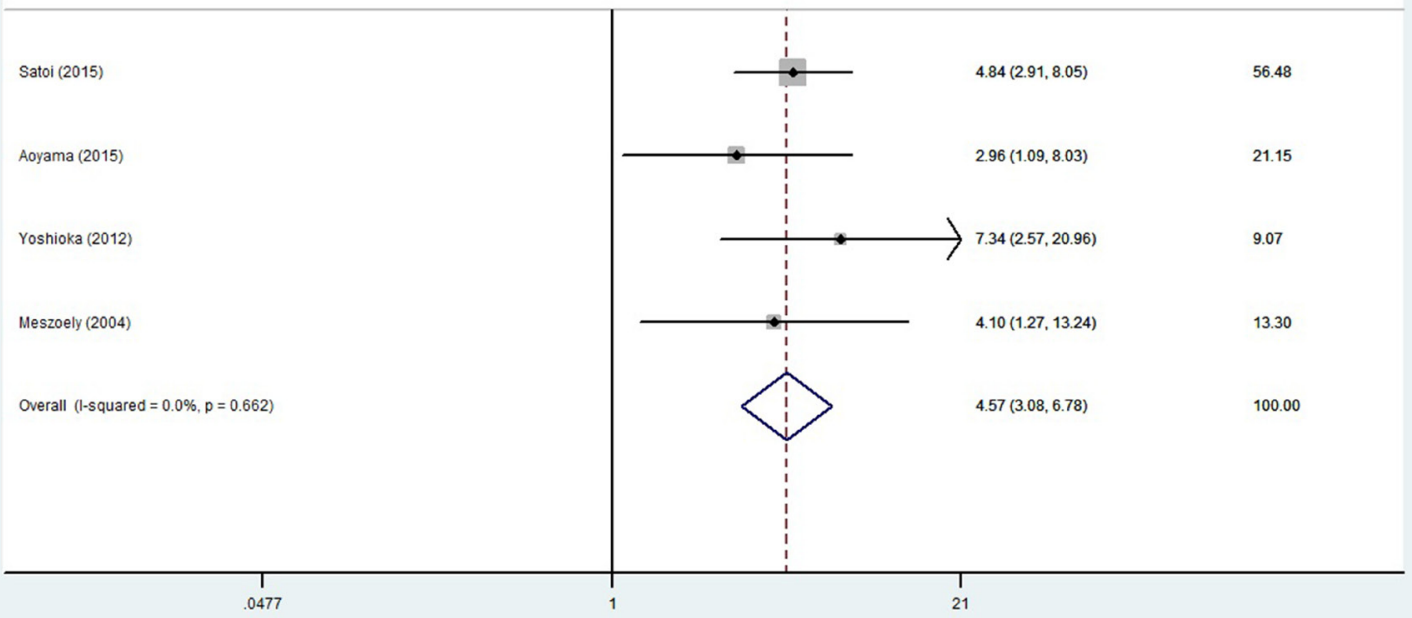

Figure 2: Forest plot of Odds ratio showing association of $\mathrm{CY}+$ status and peritoneum recurrence.

\section{HR of OS}

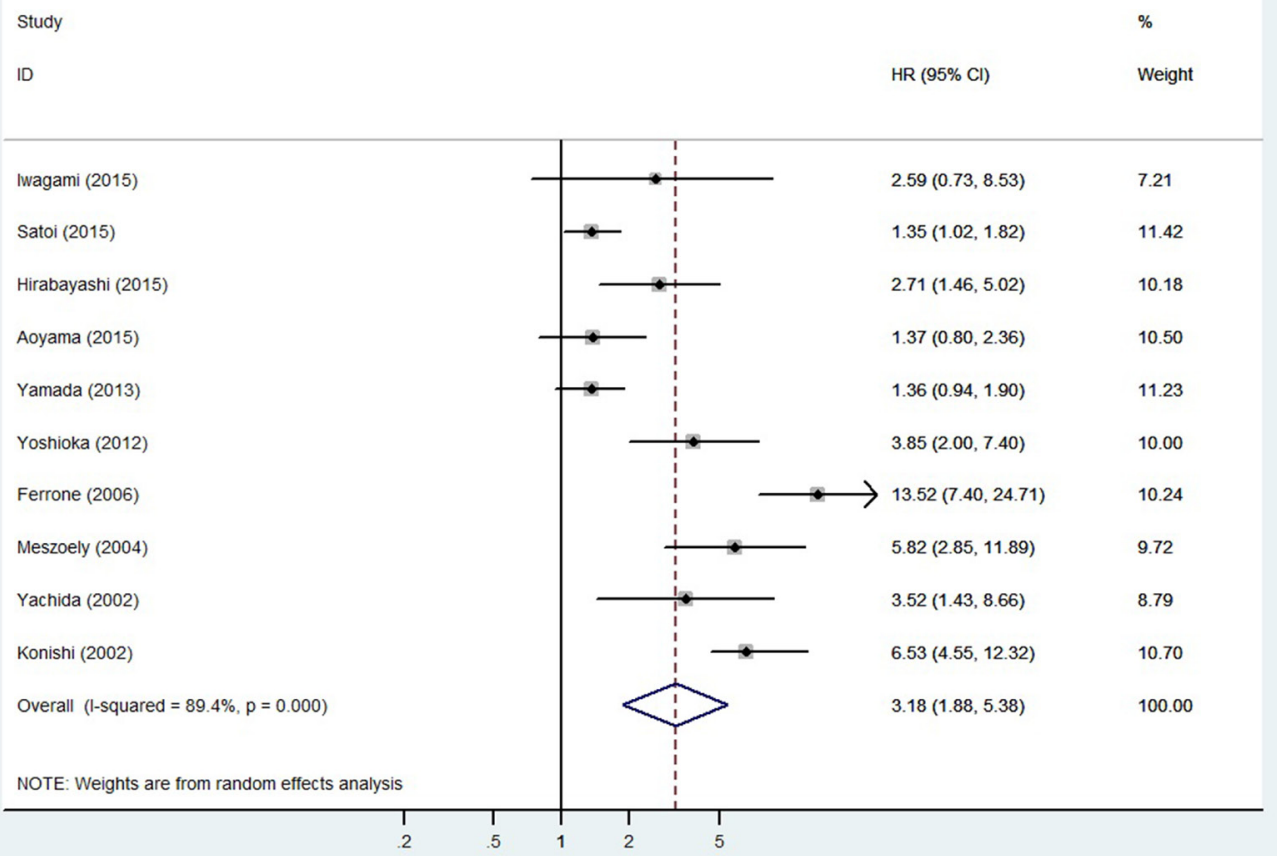

Figure 3: Forest plot of hazard ratio showing association of CY+ status and OS. 
included studies regarding OS analysis. Although the random-effect models were used to pool the OS data, the heterogeneity may have reduced the effect of largesample studies of good quality. The possible reasons for heterogeneity included the method for cytology, small number of included studies and the statistical approach for extrapolating HRs. Second, the imprecise estimation of HRs from the Kaplan-Meier curves could have adversely influenced the conclusions from our meta-analysis. Third, since all the included studies were retrospective, bias regarding selection, information and other parameters need to be considered. Inspite of these shortfalls, our results were reliable because no publication bias was detected and the subgroup analyses results were similar.

In conclusion, $\mathrm{CY}+$ status was associated with advanced tumor and poor prognosis, radical resection should not be performed on such pancreatic cancer patients.

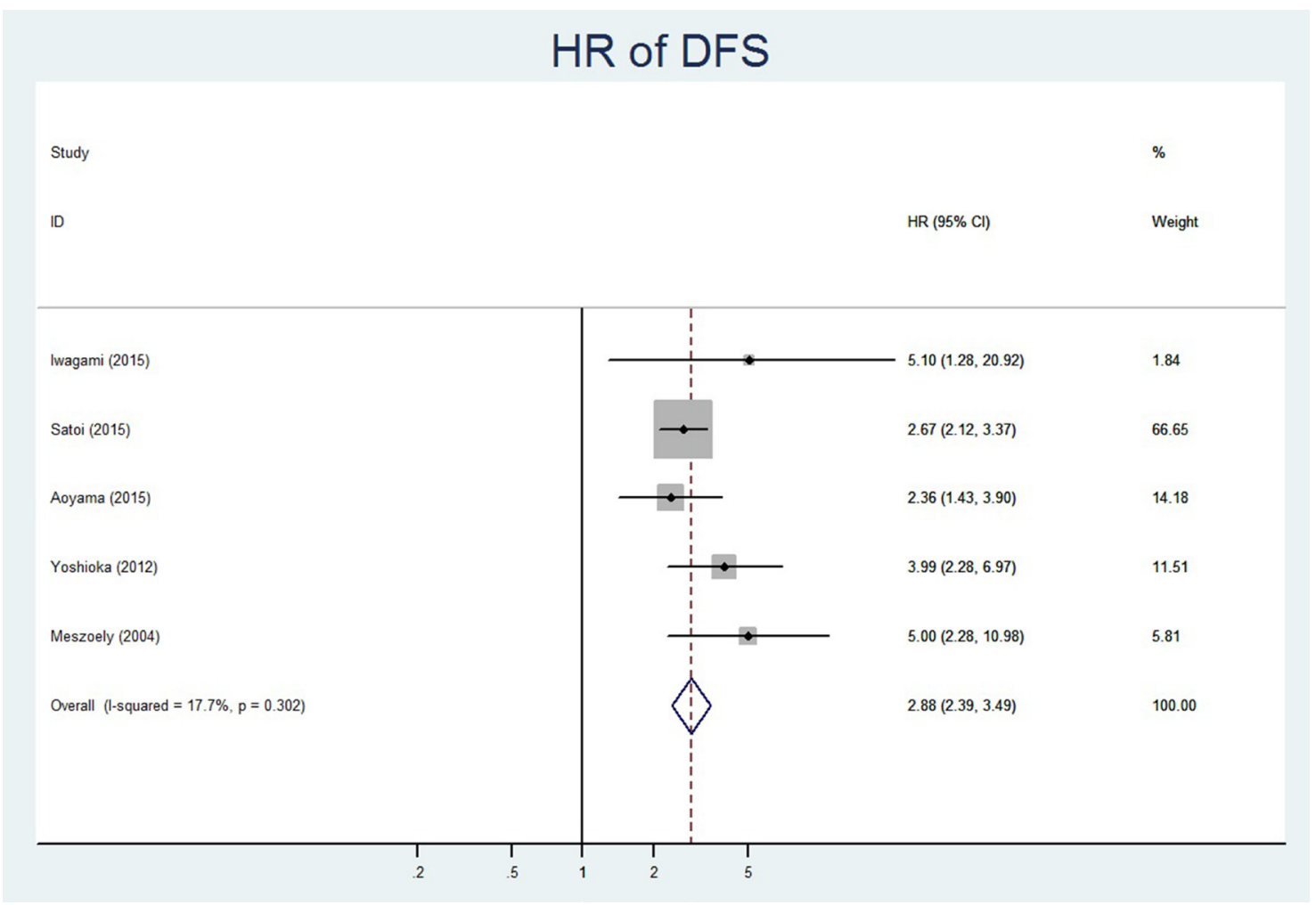

Figure 4: Forest plot of hazard ratio showing association of CY+ status and DFS.
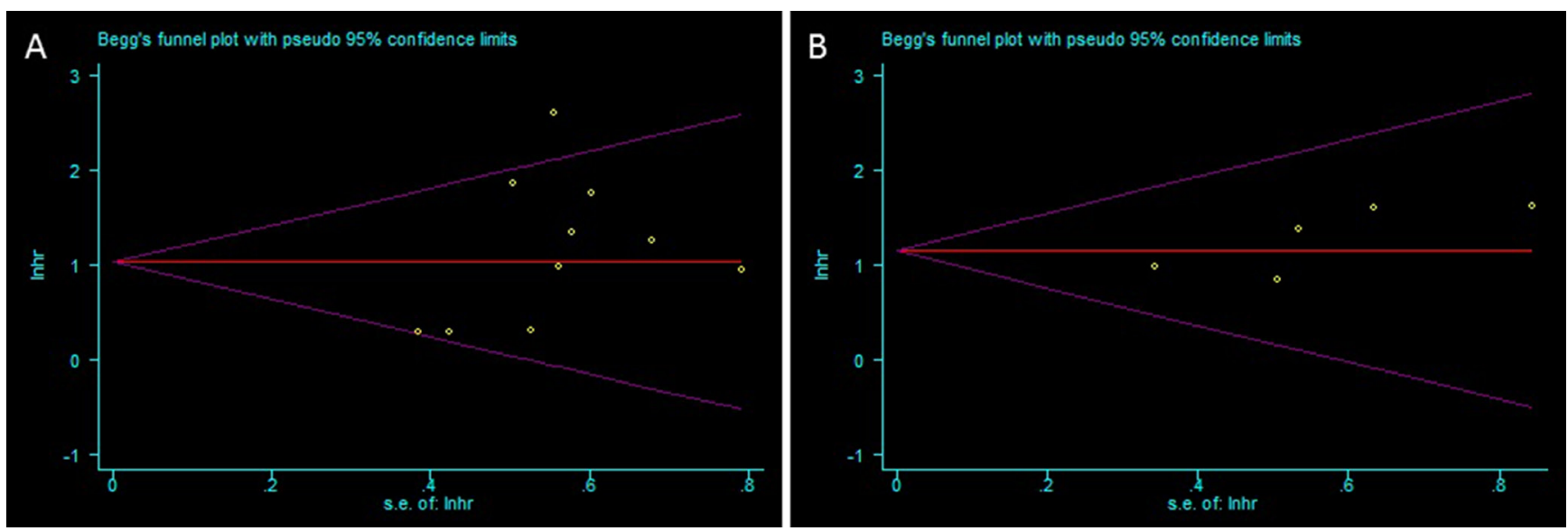

Figure 5: Funnel plots analyzing publication bias in this meta-analysis for (A) Overall survival and (B) Disease-free survival. 


\section{MATERIAL AND METHODS}

\section{Publications search and Selection criteria}

This meta-analysis was conducted in accordance with the PRISMA (Preferred Reporting Items for Systematic Reviews and Meta-Analyses) guidelines. A computerized search was performed for the terms "pancreatic cancer or pancreatic adenocarcinoma" and "peritoneal cytology" by searching PubMed, Web of Science and China National Knowledge Infrastructure(CNKI) databases in August 2016. No language restrictions were applied. The reference list in the selected articles was also checked. The criteria for including studies in the meta-analysis were: (a) clinical studies researched patients with potentially resectable pancreatic cancer; (b) CY status was measured; (c) at least one of the three endpoints (overall survival(OS), Disease-free survival(DFS) or recurrence) were reported and (d) studies contained a hazard ratio (HR) or odds ratio (OR) with the corresponding confidence interval (CI) or sufficient data to calculate them. The criteria to exclude articles from the analysis were: (a) letters, case reports, reviews and conference abstracts without original data; (b) duplicates of previous publications and (c) articles without key information such as Kaplan-Meier curves, HRs with $95 \%$ CIs or clinicopathological features.

\section{Data extraction}

Two reviewers (F. Cao and J. Li) independently considered the eligibility of potential titles and extracted the following information: first author's surname, year of publication, number of patients, method of cytology, median time of follow-up and survival, regimen of adjuvant therapy, recurrence rate, $\mathrm{HR}$ with $95 \% \mathrm{CI}$, patient age and sex, tumor location, size, tumor grade and progression, $\mathrm{T}$ and $\mathrm{N}$ stage. Discrepancies were resolved by mutual discussion or consulting with the third reviewer (A. Li).

\section{Quality assessment}

The Newcastle-Ottawa Scale was used to assess the quality of the included studies [43]. According to this scale, the maximum score could be nine points that indicated highest methodological quality. NOS score of 7 or above was considered as high quality whereas a NOS score of 3 or below was considered low quality.

\section{Main outcomes}

The primary outcomes of this study were the prognostic significance (recurrence, OS and DFS) of CY+ in potentially resectable pancreatic cancer. The secondary outcomes included calculating the Odds ratios (ORs) of clinicopathological features for $\mathrm{CY}+$ versus $\mathrm{CY}$ - patients.

\section{Statistical analysis}

HRs and 95\% CIs were used to measure the effective value. We used the HRs that was already calculated in the published studies, whenever available. If not, we calculated the HR and $95 \%$ CIs from the Kaplan-Meier survival curve or other relevant data using methods reported by Tierney and colleagues [44]. Data from the Kaplan-Meier survival curves were read using the Engauge Digitizer version 4.1. A combined HR/ $\mathrm{OR}>1$ indicated poor outcome for $\mathrm{CY}+$ patients. The chi-square $Q$ test and $\mathrm{I}^{2}$ statistics were used to explore the heterogeneity. If heterogeneity was significant $\left(P<0.1\right.$ or $\left.\mathrm{I}^{2}>50 \%\right)$, the $\mathrm{M}-\mathrm{H}$ or $\mathrm{I}-\mathrm{V}$ heterogeneity model was used. Otherwise, a fixed-effects model of MantelHaenszel was applied. Subgroup analyses for primary outcomes were performed if necessary data was available. Publication bias was analyzed using the Egger's test. All the statistical analyses were performed with the STATA/ SE software version12.0 (STATA Corporation, College Station, TX, USA).

\section{ACKNOWLEDGMENTS}

This work is partly supported by Beijing Municipal Administration of Hospitals' Youth Programme, code: QML20160806.

\section{CONFLICTS OF INTEREST}

The authors declare no conflicts of interest.

\section{Authors' contributions}

F. Cao and F. Li designed this study. F. Cao, A. $\mathrm{Li}$ and J. Li collected and analyzed the data. F. Cao and $\mathrm{J}$. Li wrote the first draft of the manuscript. All authors contributed to review the manuscript.

\section{REFERENCES}

1. Miller KD, Siegel RL, Lin CC, Mariotto AB, Kramer JL, Rowland JH, Stein KD, Alteri R, Jemal A. Cancer treatment and survivorship statistics, 2016. CA Cancer J Clin. 2016; 66:271-289.

2. Siegel RL, Miller KD, Jemal A. Cancer statistics, 2016. CA Cancer J Clin. 2016; 66:7-30.

3. Chen W, Zheng R, Baade PD, Zhang S, Zeng H, Bray F, Jemal A, Yu XQ, He J. Cancer statistics in China, 2015. CA Cancer J Clin. 2016; 66:115-132.

4. Kamisawa T, Wood LD, Itoi T, Takaori K. Pancreatic cancer. LANCET. 2016; 388:73-85.

5. Allen VB, Gurusamy KS, Takwoingi Y, Kalia A, Davidson BR. Diagnostic accuracy of laparoscopy following computed tomography (CT) scanning for 
assessing the resectability with curative intent in pancreatic and periampullary cancer. Cochrane Database Syst Rev. 2016; 7:D9323.

6. Paiella S, Sandini M, Gianotti L, Butturini G, Salvia R, Bassi C. The prognostic impact of para-aortic lymph node metastasis in pancreatic cancer: A systematic review and meta-analysis. Eur J Surg Oncol. 2016; 42:616-624.

7. Oh SY, Edwards A, Mandelson MT, Hahn H, Alseidi A, Biehl T, Kozarek RA, Rocha FG, Helton S, Picozzi VJ. Localized pancreatic cancer with positive peritoneal cytology as a sole manifestation of metastatic disease: a single-institution experience. Am J Surg. 2016.

8. Simojoki M, Santala M, Vuopala S, Kauppila A. The prognostic value of peritoneal cytology in ovarian cancer. Eur J Gynaecol Oncol. 1999; 20:357-360.

9. Lee B, Suh DH, Kim K, No JH, Kim YB. Influence of positive peritoneal cytology on prognostic factors and survival in early-stage endometrial cancer: a systematic review and meta-analysis. Jpn J Clin Oncol. 2016.

10. Ikoma N, Blum M, Chiang YJ, Estrella JS, RoyChowdhuri S, Fournier K, Mansfield P, Ajani JA, Badgwell BD. Yield of Staging Laparoscopy and Lavage Cytology for Radiologically Occult Peritoneal Carcinomatosis of Gastric Cancer. Ann Surg Oncol. 2016.

11. Iwagami Y, Eguchi H, Wada H, Tomimaru Y, Hama N, Kawamoto K, Kobayashi S, Mori M, Doki Y, Nagano H. Implications of peritoneal lavage cytology in resectable leftsided pancreatic cancer. Surg Today. 2015; 45:444-450.

12. Satoi S, Murakami Y, Motoi F, Uemura K, Kawai M, Kurata M, Sho M, Matsumoto I, Yanagimoto H, Yamamoto T, Mizuma M, Unno M, Hashimoto Y, et al. Reappraisal of peritoneal washing cytology in 984 patients with pancreatic ductal adenocarcinoma who underwent margin-negative resection. J Gastrointest Surg. 2015; 19:6-14, 14.

13. Hirabayashi K, Imoto A, Yamada M, Hadano A, Kato N, Miyajima Y, Ito H, Kawaguchi Y, Nakagohri T, Mine T, Nakamura N. Positive Intraoperative Peritoneal Lavage Cytology is a Negative Prognostic Factor in Pancreatic Ductal Adenocarcinoma: A Retrospective Single-Center Study. Front Oncol. 2015; 5:182.

14. Aoyama T, Katayama Y, Murakawa M, Shiozawa M, Morimoto M, Yamamoto N, Yoshikawa T, Rino Y, Masuda M, Morinaga S. Clinical implication of peritoneal cytology in the pancreatic cancer patients who underwent curative resection followed by adjuvant gemcitabine or S-1 chemotherapy. Hepatogastroenterology. 2015; 62:200-206.

15. Yamada S, Fujii T, Kanda M, Sugimoto H, Nomoto S, Takeda S, Nakao A, Kodera Y. Value of peritoneal cytology in potentially resectable pancreatic cancer. Br J Surg. 2013; 100:1791-1796.

16. Yoshioka R, Saiura A, Koga R, Arita J, Takemura N, Ono Y, Yamamoto J, Yamaguchi T. The implications of positive peritoneal lavage cytology in potentially resectable pancreatic cancer. World J Surg. 2012; 36:2187-2191.
17. Ferrone CR, Haas B, Tang L, Coit DG, Fong Y, Brennan MF, Allen PJ. The influence of positive peritoneal cytology on survival in patients with pancreatic adenocarcinoma. J Gastrointest Surg. 2006; 10:1347-1353.

18. Meszoely IM, Lee JS, Watson JC, Meyers M, Wang H, Hoffman JP. Peritoneal cytology in patients with potentially resectable adenocarcinoma of the pancreas. Am Surg. 2004; 70:208-213, 213-214.

19. Konishi M, Kinoshita T, Nakagohri T, Inoue K, Oda T, Takahashi S. Prognostic value of cytologic examination of peritoneal washings in pancreatic cancer. Arch Surg. 2002; 137:475-480.

20. Yachida S, Fukushima N, Sakamoto M, Matsuno Y, Kosuge T, Hirohashi S. Implications of peritoneal washing cytology in patients with potentially resectable pancreatic cancer. Br J Surg. 2002; 89:573-578.

21. Edge SB, Compton CC. The American Joint Committee on Cancer: the 7th edition of the AJCC cancer staging manual and the future of TNM. Ann Surg Oncol. 2010; 17:1471-1474.

22. Tempero MA, Arnoletti JP, Behrman S, Ben-Josef E, Benson AR, Berlin JD, Cameron JL, Casper ES, Cohen SJ, Duff M, Ellenhorn JD, Hawkins WG, Hoffman JP, et al. Pancreatic adenocarcinoma. J Natl Compr Canc Netw. 2010; 8:972-1017.

23. Isaji S, Kawarada Y, Uemoto S. Classification of pancreatic cancer: comparison of Japanese and UICC classifications. Pancreas. 2004; 28:231-234.

24. Clark CJ, Traverso LW. Positive peritoneal lavage cytology is a predictor of worse survival in locally advanced pancreatic cancer. Am J Surg. 2010; 199:657-662.

25. Yamada S, Takeda S, Fujii T, Nomoto S, Kanazumi N, Sugimoto H, Kasuya H, Kodera Y, Nagasaka T, Morita S, Nakao A. Clinical implications of peritoneal cytology in potentially resectable pancreatic cancer: positive peritoneal cytology may not confer an adverse prognosis. Ann Surg. 2007; 246:254-258.

26. Merchant NB, Conlon KC, Saigo P, Dougherty E, Brennan MF. Positive peritoneal cytology predicts unresectability of pancreatic adenocarcinoma. J Am Coll Surg. 1999; 188:421-426.

27. Thomassen I, Lemmens VE, Nienhuijs SW, Luyer MD, Klaver YL, de Hingh IH. Incidence, prognosis, and possible treatment strategies of peritoneal carcinomatosis of pancreatic origin: a population-based study. Pancreas. $2013 ; 42: 72-75$.

28. Cabalag CS, Chan ST, Kaneko Y, Duong CP. A systematic review and meta-analysis of gastric cancer treatment in patients with positive peritoneal cytology. Gastric Cancer. 2015; 18:11-22.

29. Kano Y, Kosugi S, Ishikawa T, Otani T, Muneoka Y, Sato Y, Hanyu T, Hirashima K, Bamba T, Wakai T. Prognostic significance of peritoneal lavage cytology at three cavities in patients with gastric cancer. Surgery. 2015; 158:1581-1589. 
30. Uras C, Altinkaya E, Yardimci H, Goksel S, Yavuz N, Kaptanoglu L, Akcal T. Peritoneal cytology in the determination of free tumour cells within the abdomen in colon cancer. Surg Oncol. 1996; 5:259-263.

31. Von Hoff DD, Ervin T, Arena FP, Chiorean EG, Infante J, Moore M, Seay T, Tjulandin SA, Ma WW, Saleh MN, Harris M, Reni M, Dowden S, et al. Increased survival in pancreatic cancer with nab-paclitaxel plus gemcitabine. N Engl J Med. 2013; 369:1691-1703.

32. De Vita F, Ventriglia J, Febbraro A, Laterza MM, Fabozzi A, Savastano B, Petrillo A, Diana A, Giordano G, Troiani T, Conzo G, Galizia G, Ciardiello F, et al. NAB-paclitaxel and gemcitabine in metastatic pancreatic ductal adenocarcinoma (PDAC): from clinical trials to clinical practice. BMC Cancer. 2016; 16:709.

33. Reure J, Follana P, Gal J, Evesque L, Cavaglione G, Saint A, Francois E. Effectiveness and Tolerability of Maintenance Capecitabine Administrated to Patients with Metastatic Pancreatic Cancer Treated with First-Line FOLFIRINOX. Oncology-Basel. 2016; 90:261-266.

34. Wu W, He J, Cameron JL, Makary M, Soares K, Ahuja N, Rezaee N, Herman J, Zheng L, Laheru D, Choti MA, Hruban RH, Pawlik TM, et al. The impact of postoperative complications on the administration of adjuvant therapy following pancreaticoduodenectomy for adenocarcinoma. Ann Surg Oncol. 2014; 21:2873-2881.

35. Allen VB, Gurusamy KS, Takwoingi Y, Kalia A, Davidson BR. Diagnostic accuracy of laparoscopy following computed tomography (CT) scanning for assessing the resectability with curative intent in pancreatic and periampullary cancer. Cochrane Database Syst Rev. 2016; 7:D9323.

36. Tentes AA, Kyziridis D, Kakolyris S, Pallas N, Zorbas G, Korakianitis O, Mavroudis C, Courcoutsakis N, Prasopoulos P. Preliminary results of hyperthermic intraperitoneal intraoperative chemotherapy as an adjuvant in resectable pancreatic cancer. Gastroenterol Res Pract. 2012; 2012:506571.
37. Tentes AA, Stamou K, Pallas N, Karamveri C, Kyziridis D, Hristakis C. The effect of hyperthermic intraoperative intraperitoneal chemotherapy (HIPEC) as an adjuvant in patients with resectable pancreatic cancer. Int $\mathrm{J}$ Hyperthermia. 2016:1-5.

38. Moore MJ, Goldstein D, Hamm J, Figer A, Hecht JR, Gallinger S, Au HJ, Murawa P, Walde D, Wolff RA, Campos D, Lim R, Ding K, et al. Erlotinib plus gemcitabine compared with gemcitabine alone in patients with advanced pancreatic cancer: a phase III trial of the National Cancer Institute of Canada Clinical Trials Group. J Clin Oncol. 2007; 25:1960-1966.

39. Johansson $\mathrm{H}$, Andersson $\mathrm{R}$, Bauden $\mathrm{M}$, Hammes $\mathrm{S}$, Holdenrieder S, Ansari D. Immune checkpoint therapy for pancreatic cancer. World J Gastroenterol. 2016; 22:9457-9476.

40. Brahmer JR, Tykodi SS, Chow LQ, Hwu WJ, Topalian SL, Hwu P, Drake CG, Camacho LH, Kauh J, Odunsi K, Pitot HC, Hamid O, Bhatia S, et al. Safety and activity of antiPD-L1 antibody in patients with advanced cancer. N Engl J Med. 2012; 366:2455-2465.

41. Wright GP, Poruk KE, Zenati MS, Steve J, Bahary N, Hogg ME, Zuriekat AH, Wolfgang CL, Zeh HR, Weiss MJ. Primary Tumor Resection Following Favorable Response to Systemic Chemotherapy in Stage IV Pancreatic Adenocarcinoma with Synchronous Metastases: a Biinstitutional Analysis. J Gastrointest Surg. 2016.

42. Crippa S, Bittoni A, Sebastiani E, Partelli S, Zanon S, Lanese A, Andrikou K, Muffatti F, Balzano G, Reni M, Cascinu S, Falconi M. Is there a role for surgical resection in patients with pancreatic cancer with liver metastases responding to chemotherapy? Eur J Surg Oncol. 2016.

43. Stang A. Critical evaluation of the Newcastle-Ottawa scale for the assessment of the quality of nonrandomized studies in meta-analyses. Eur J Epidemiol. 2010; 25:603-605.

44. Tierney JF, Stewart LA, Ghersi D, Burdett S, Sydes MR. Practical methods for incorporating summary time-to-event data into meta-analysis. Trials. 2007; 8:16. 